\title{
The glyceraldehyde-3-phosphate dehydrogenase gene of Moniliophthora perniciosa, the causal agent of witches' broom disease of Theobroma cacao
}

\author{
Juliana O. Lima ${ }^{1}$, Jorge F. Pereira ${ }^{2}$, Johana Rincones ${ }^{3}$, Joan G. Barau ${ }^{3}$, Elza F. Araújo ${ }^{1}$, \\ Gonçalo A.G. Pereira ${ }^{3}$ and Marisa V. Queiroz ${ }^{1}$ \\ ${ }^{1}$ Departamento de Microbiologia, Universidade Federal de Viçosa, Viçosa, MG, Brazil. \\ ${ }^{2}$ Núcleo de Biotecnologia Aplicada a Cereais de Inverno, Embrapa Trigo, Passo Fundo, RS, Brazil. \\ ${ }^{3}$ Departamento de Genética e Evolução, Universidade Estadual de Campinas, Campinas, SP, Brazil.
}

\begin{abstract}
This report describes the cloning, sequence and expression analysis of the glyceraldehyde-3-phosphate dehydrogenase (GAPDH) gene of Moniliophthora perniciosa, the most important pathogen of cocoa in Brazil. Southern blot analysis revealed the presence of a single copy of the GAPDH gene in the M. perniciosa genome (MpGAPDH). The complete MpGAPDH coding sequence contained 1,461 bp with eight introns that were conserved in the GAPDH genes of other basidiomycete species. The cis-elements in the promoter region of the MpGAPDH gene were similar to those of other basidiomycetes. Likewise, the MpGAPDH gene encoded a putative 339 amino acid protein that shared significant sequence similarity with other GAPDH proteins in fungi, plants, and metazoans. Phylogenetic analyses clustered the MPGAPDH protein with other homobasidiomycete fungi of the family Tricholomataceae. Expression analysis of the MpGAPDH gene by real-time PCR showed that this gene was more expressed $(\sim 1.3 \mathrm{X})$ in the saprotrophic stage of this hemibiotrophic plant pathogen than in the biotrophic stage when grown in cacao extracts.
\end{abstract}

Key words: glyceraldehyde-3-phosphate dehydrogenase gene, Moniliophthora perniciosa, witches' broom.

Received: June 26, 2008; Accepted: December 5, 2008.

Glyceraldehyde-3-phosphate dehydrogenase (GAPDH) is a key enzyme of glycolysis, although other functions have been proposed for this protein (Sirover, 1999), including a role in the pathogenesis of prokaryotic and eukaryotic pathogens (Barbosa et al., 2006; Egea et al., 2007). In filamentous fungi, the GAPDH gene is generally present as a single copy (Punt et al., 1988; Harmsen et al., 1992; Hirano et al., 1999; Kuo et al., 2004; Vastag et al., 2004; Neveu et al., 2007; Liao et al., 2008), but some species may contain two (Harmsen et al., 1992) or three (Wolff and Arnau, 2002) copies of the gene, not all of which are necessarily transcriptionally active (Harmsen et al., 1992; Wolff and Arnau, 2002). The GAPDH gene is frequently very highly expressed, with GAPDH protein accounting for up to $5 \%$ of the total content of soluble cellular proteins in various eukaryotes (Piechaczyk et al., 1984). This elevated expression raises interesting practical questions about the regulation of this gene.. The eukaryotic GAPDH gene is controlled by a highly active promoter that has been used to construct transformation systems for numerous fungal spe-

Send correspondence to Marisa V. Queiroz. Departamento de Microbiologia, Universidade Federal de Viçosa, 36571-000 Viçosa, MG, Brazil. E-mail: mvqueiro@ufv.br. cies (Ridder and Osiewacz, 1992; Schuren and Wessels, 1994; Cheng et al., 2001; Irie et al., 2001; Kuo et al., 2004; Neveu et al., 2007; Kuo and Huang, 2008).

The basidiomycete Moniliophthora perniciosa (Homobasidiomycetes, Agaricales, Tricholomataceae) is the causal agent of witches' broom disease in cacao plants (Theobroma cacao). This hemibiotrophic phytopathogen initially develops as a monokaryotic/biotrophic mycelium that shows slow, low density growth, during which it occupies the intercellular space of infected tissue. After this monokaryotic/biotrophic phase, the mycelium shifts to a dikaryotic/saprotrophic phase of vigorous growth in which it colonizes inter- and intracellular tissues and rapidly destroys the infected tissues (Evans, 1980; Rincones et al., 2008). This disease has had a significant socio-economic effect on Brazilian cocoa production. In view of the economic importance of this phytopathogen, in 2000 a $M$. perniciosa genome sequencing consortium was established to investigate the molecular basis of this pathogen and its interaction with cacao plants (Witches' broom project). A databank of genomic sequences, based on a $6 \mathrm{X}$ coverage of the M. perniciosa genome, is currently being used for gene discovery and to support other experiments related to gene expression, physiology and histology. In this context, the 
creation of an efficient transformation system for $M$. perniciosa is of prime importance in order to allow functional genomic studies of this pathogen during its interaction with the host plant.

Our group recently established a heterologous transformation system for M. perniciosa based on the hygromycin B phosphotransferase $(h p h)$ gene under control of the GAPDH promoter of Aspergillus nidulans (Lima et al., 2003) and Agaricus bisporus (Lopes et al., 2008). In the present study, we cloned the M. perniciosa GAPDH gene $(M p G A P D H)$ and analyzed its complete nucleotide sequence. The molecular organization, homology with GAPDH proteins of other fungi, and differential expression were also analyzed. The potential use of the homologous $G A P D H$ promoter in future transformation experiments is discussed.

The fungal strain used was $M$. perniciosa $\mathrm{CP} 02$, the same strain as used in the Witches' broom project. The total DNA from this strain was used to amplify a 396 bp DNA fragment containing part of the $M p G A P D H$ gene, with the primers 5' GCGAACTTTTCAATGGTGGT 3' and 5' AACGAGTGCGTACCCTCAAC 3'. These primers were designed based on sequences present in the genome-sequencing consortium database (Witches' broom project) that showed sequence similarity to GAPDH genes of other fungi. This DNA fragment was also used as a probe to isolate recombinant phages from a genomic library of $M$. perniciosa constructed in the bacteriophage $\lambda \mathrm{EMBL} 3$. DNA sequencing was done in a MegaBACE 500 sequencer (Amersham Biosciences). Subsequent analyses of DNA and protein sequences were done with the BLAST algorithm and the programs CLUSTAL W and PAUP* (version 4.0). The GenBank accession number for the M. perniciosa $G A P D H$ gene sequence is DQ099333.

Southern blot analysis was done according to standard procedures (Sambrook and Russell, 2001). Total DNA $(3 \mu \mathrm{g})$ was digested with restriction enzymes (BamHI, PstI and $\mathrm{SacI}$ ) and the resulting fragments then separated on a $0.7 \%$ agarose gel. Hybridizations were done at $65^{\circ} \mathrm{C}$ using the Gene Images Random Prime Labeling Module and Gene Images CDP-Star Detection Module kits, according to the manufacturer's instructions (Amersham Biosciences).

The expression profile of the MpGAPDH gene was assessed by using real-time PCR with SYBRGreen in an ABI Prism 7500 Sequence Detection System (Applied Biosystems, Foster City, CA). Total RNA was extracted with an RNeasy plant minikit (Qiagen) from M. perniciosa biotrophic-like and saprotrophic mycelia grown in synthetic media containing 5\% glycerol and induced with a $1 \%$ cacao-meristem extract, according to Meinhardt et al. (2006). Control RNA was obtained from the saprotrophic mycelium of M. perniciosa grown under the same conditions, but without the cacao extract. The primers 5' GGAT CTGTCGGTGCTCACTA 3' and 5' AACGTACATGG
GTGCATCA 3' were used to amplify a $100 \mathrm{bp}$ amplicon of the M. perniciosa GAPDH gene, with mp- $\beta$-actin1 (primers: 5' CCCTTCTATCGTCGGTCGT 3' and 5' AGGATA CCACGCTTGGATTG 3') and mp-60S ribosomal RNA (primers: 5' CAACTCTCTTTGAAGCGTTGC 3' and 5' CGAGGAACATGACGCAATTA 3') being used as internal housekeeping genes to normalize gene expression. Full details of the procedures used in this assay have been described elsewhere (Rincones et al., 2008).

Southern hybridization of digested $M$. perniciosa genomic DNA with the 396 bp fragment of the $M p G A P D H$ gene revealed a single band in each digestion (BamHI, PstI, and $S a c I$ ), indicating the presence of only one copy for this gene (data not shown). This result agrees with data for several fungal species in which a single copy of the GAPDH gene has been reported (Punt et al., 1988; Harmsen et al., 1992; Hirano et al., 1999; Kuo et al., 2004; Vastag et al., 2004; Neveu et al., 2007; Liao et al., 2008). When the same $396 \mathrm{bp}$ fragment of the $M p G A P D H$ gene was used as a probe to screen a phage genomic library, five positive clones were isolated. A DNA fragment of $\sim 4 \mathrm{~kb}$ from one of these phages was subcloned into the pBluescript II KS+ vector (Stratagene) and partially sequenced. The resulting sequence was incomplete, lacking the 3 ' region of the gene (approximately $700 \mathrm{bp}$ ). To complete the sequence, we mined the database of the Witches' broom project, from which several reads were retrieved through BLASTn comparisons and assembled in silico using the software Gene Projects (Carazzolle et al., 2007). The coding region of the $M p G A P D H$ gene consisted of 1,461 bp. We sequenced an additional $799 \mathrm{bp}$ of the promoter region and $203 \mathrm{bp}$ of the terminator region. The cDNA sequence of the $M p G A P D H$ gene was also obtained from the Witches' broom project database. The software Gene Projects retrieved six cDNA reads that clustered to form two contigs spanning the whole transcribed region of the $M p G A P D H$ gene. The presence of eight introns was determined by aligning the genomic and cDNA sequences. These introns $(50,65,49,54,58,57,56$ and $52 \mathrm{bp}$ ) show consensus 5 '-end (GT) and 3'-end (PyAG) sequences and internal sequences (such as TAAG and CAAT) that are common to introns of filamentous fungi (Gurr et al., 1987). Most introns of fungal GAPDH genes are located at the 5'-end. Although the position of some of these introns is highly conserved within the Basidiomycetes and Ascomycetes, only one intron position is conserved between these two groups (Harmsen et al., 1992) and no intron position is conserved when compared to the Zygomycetes (Wolff and Arnau, 2002). Moreover, the average number of introns is higher in GAPDH genes of Basidiomycetes than of Ascomycetes. A rare intron organization has been reported for the GAPDH genes of $A$. nidulans, Claviceps purpurea, Blumeria graminis f. sp. hordei and Pseudozyma flocculosa, with one intron positioned outside the structural region (Punt et al., 1988; Christiansen et al., 1997; Neveu et al., 2007). Apart from 
their evolutionary significance, introns from GAPDH genes can have other roles. Thus, for instance, one of the introns of the GAPDH gene has an important role in the high level of protein expression in Phanerochaete chrysosporium (Kuo and Huang, 2008) while other introns are important for the identification of some ectomycorrhizal basidiomycetes (Kreuzinger et al., 1996).

Sequence analysis of the upstream region of the $M$. perniciosa GAPDH gene revealed the presence of several putative cis-elements, namely a putative TATA box (TATAAA) located at $-73 \mathrm{bp}$ and three putative CAAT boxes (CAAT) at $-153,-106$ and -86 bp that were positioned using the translation start point as a reference. The putative TATA box was followed by a long stretch of pyrimidine residues upstream of the start ATG codon, as also observed in many fungal GAPDH genes (Gurr et al., 1987). In addition to the $c i s$-elements identified in the $M p G A P D H$ promoter, the region surrounding the start codon (CCCACCATGGT) contained a purine (adenine) at the $-3 \mathrm{bp}$ position that is important for ribosome targeting (Gurr et al., 1987). Additional conserved sequences described for the GAPDH promoter regions of the ascomycetes $A$. nidulans and $A$. niger, known as the $p g k, q a, g p d$, and qut boxes (Punt et al., 1990) were not found in the MpGAPDH gene, in agreement with the observations in other basidiomycetes (Harmsen et al., 1992; Kuo et al., 2004) and one zygomycete (Wolff and Arnau, 2002).

This lack of similarity among the GAPDH promoter regions of different fungal phyla may explain why the regulatory region of an ascomycete $G A P D H$ gene is usually poorly recognized by the transcriptional machinery of basidiomycete fungi (Harmsen et al., 1992). For instance, the $A$. nidulans GAPDH promoter used in the transformation system described for M. perniciosa appears to be active at a low rate since all of the hygromycin-resistant transformants analyzed showed a high copy number of the pAN7-1 vector (Lima et al., 2003). We expect that the future use of the homologous GAPDH promoter described here will increase the efficiency of transformation and the number of single vector integrations in $M$. perniciosa, as has been described in a number of other fungal species (Ridder and Osiewacz, 1992; Schuren and Wessels, 1994; Cheng et al., 2001; Irie et al., 2001). The termination codon TAA, the most frequently found codon in filamentous fungi, was also present in the M. perniciosa GAPDH gene. The 3' untranslated sequence was characterized as AT-rich, although the consensus sequence (AATAAA) described by Gurr et al. (1987) was not identified.

The M. perniciosa GAPDH gene encoded a 339 amino acid protein (MPGAPDH) with a calculated molecular mass of $36.9 \mathrm{kDa}$. The M. perniciosa GAPDH protein showed high sequence similarity to GAPDH proteins of other organisms: $81.7 \%$ identity with the GAPDH of Armillariella tabescens, $78.5 \%$ with that of Lentinus edodes, $77.3 \%$ with $P$. chrysosporium, $76.1 \%$ with $A$. bisporus and $70.3 \%$ with Ustilago maydis. The $M$. perniciosa GAPDH protein was also highly similar to the GAPDH protein of some plants and animals. The cysteine residue that defines the protein's catalytic site (binding site for glyceraldehyde-3-phosphate) was located at position 150 in the MPGAPDH protein (Figure 1), the same position found in the basidiomycete $A$. bisporus and the zygomycete Rhizomucor miehei (Vastag et al., 2004). In the basidiomycetes Schizophyllum commune, P. chrysosporium, and L. edodes, this cysteine occurs at position 151 (Harmsen et al., 1992; Hirano et al., 1999). An evolutionary tree based on the GAPDH amino acid sequence of 42 species (Figure 2) showed separation of the basidiomycetes, zygomycetes and ascomycetes, and confirmed that MPGAPDH clustered with other homobasidiomycetes of the family Tricholomataceae. Furthermore, the yeast-like ascomycetes (Saccharomycetes) were separated from the filamentous ascomycetes and the basidiomycetes were divided into homo- and heterobasidiomycete species, except for Thanatephorus cucumeris, which clustered with the heterobasidiomycetes species analyzed. These findings agreed

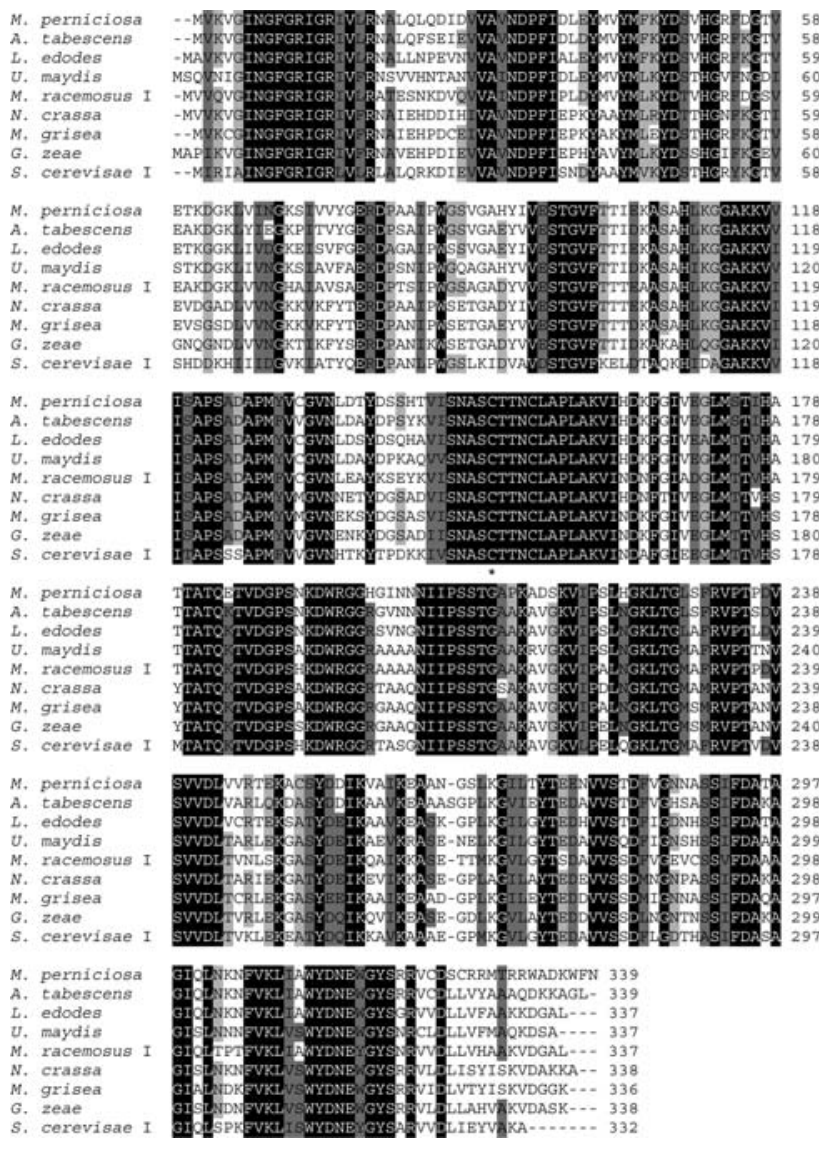

Figure 1 - Multiple alignment of the deduced amino acid sequence of $M$. perniciosa GAPDH and other fungal GAPDH proteins (see Figure 2 for GenBank accession numbers). Gaps (-) were introduced to maximize the alignment. The level of amino acid similarity among the sequences is indicated by different shades of gray. A conserved cysteine residue $\left(\mathrm{C}^{150}\right.$ in $M$. perniciosa) that is important for the binding of glyceraldehyde-3-phosphate in the catalytic site is indicated with an asterisk $(*)$. 


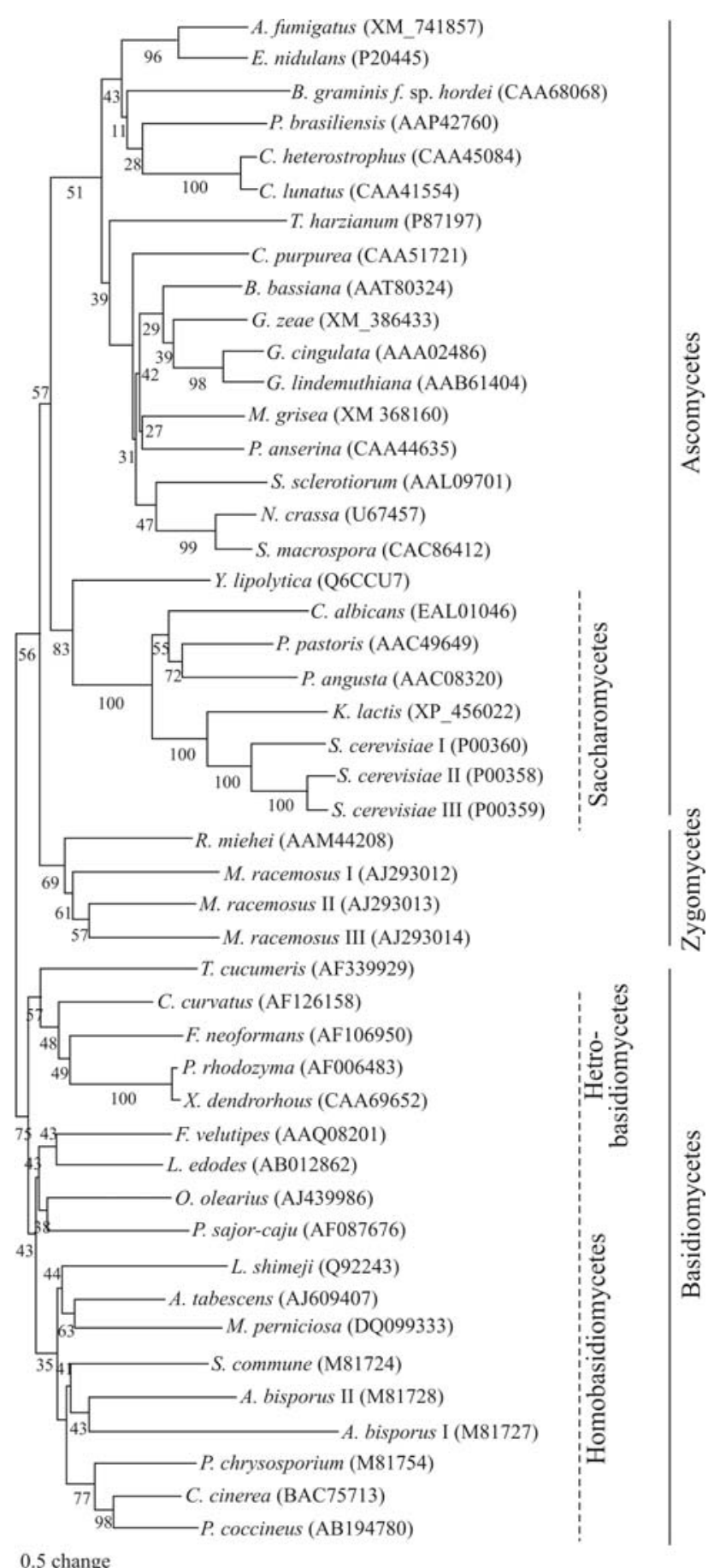

0.5 change

Figure 2 - An unrooted phylogenetic tree showing the relationship between GAPDH proteins from M. perniciosa and other fungi (GenBank accession numbers are indicated in parentheses). The tree was built using the neighbor-joining method (Saitou and Nei, 1987). The numbers above or below each horizontal line correspond to the frequency of each branch in 1000 bootstraps.

with the trees previously described by others (Wolff and Arnau, 2002; Neveu et al., 2007).

Real-time PCR analysis revealed that the MpGAPDH gene was differentially expressed in biotrophic-like (-1.528 fold-change) and saprotrophic (-1.161 fold-change) mycelia grown in cacao extract $(\sim 32 \%$ lower expression in the former compared to the latter). This gene was also repressed in both types of mycelia when compared to control saprotrophic mycelia grown in glycerol. This finding agreed with results for M. perniciosa cultured in vitro and with published DNA microarray data (Rincones et al., 2008). Biotrophic mycelia of M. perniciosa are only found in infected cacao tissue during the "green broom" stage of the disease and are very difficult to maintain in vitro (Evans, 1980). Spores of this homothallic species grown on typical glucose-containing culture media rapidly undergo dikaryotization by selfing to produce the saprotrophic phase, unless the media contains cocoa or potato calluses (Evans, 1980; Griffith and Hedger, 1994) or glycerol is used as the sole carbon source (Meinhardt et al., 2006). Since GAPDH is one of the key enzymes of glycolysis and the biotrophic phase is unable to grow on glucose as a sole carbon source, the repression of this gene in biotrophic mycelia would be expected. Consequently, the differential regulation of $M p G A P D H$ gene expression described here must be considered when its promoter is used to construct a transformation vector.

\section{Acknowledgments}

This work was supported by the Brazilian agencies Conselho Nacional de Desenvolvimento Científico e Tecnológico (CNPq), Coordenação de Aperfeiçoamento de Pessoal de Nível Superior (CAPES), Fundação de Amparo à Pesquisa do Estado de São Paulo (FAPESP, grant no. 05/60432-5) and Secretaria de Agricultura do Estado da Bahia (SEAGRI).

\section{References}

Barbosa MS, Báo SN, Andreotti PF, Faria FP, Felipe MSS, Feitosa LS, Mendes-Giannini MJS and Soares CMA (2006) Glyceraldehyde-3-phosphate dehydrogenase of Paracoccidioides brasiliensis is a cell surface protein involved in fungal adhesion to extracellular matrix proteins and interaction with cells. Infect Immun 74:382-389.

Carazzolle MF, Formighieri EF, Digiampietri LA, Araújo MRR, Costa GGL and Pereira GAG (2007) Gene projects: A genome Web tool for ongoing mining and annotation applied to CitEST. Genet Mol Biol 30:1030-1036.

Cheng YL, Belzile F, Tanguay P, Bernier L and Bélanger RR (2001) Establishment of a gene transfer system for Pseudozyma flocculosa, an antagonistic fungus of powdery mildew fungi. Mol Genet Genomics 266:96-102.

Christiansen SK, Justesen AF and Giese H (1997) Disparate sequence characteristics of the Erysiphe graminis f sp hordei glyceraldehyde-3-phosphate dehydrogenase gene. Curr Genet 31:525-529.

Egea L, Aguilera L, Giménez R, Sorolla MA, Aguilar J, Badía J and Baldoma L (2007) Role of secreted glyceraldehyde3-phosphate dehydrogenase in the infection mechanism of enterohemorrhagic and enteropathogenic Escherichia coli: Interaction of the extracellular enzyme with human plasminogen and fibrinogen. Int J Biochem Cell Biol 39:11901203. 
Evans HC (1980) Pleomorphism in Crinipellis perniciosa, causal agent of witches' broom disease of cocoa. Trans Br Mycol Soc 74:515-523.

Griffith GW and Hedger JN (1994) Dual culture of Crinipellis perniciosa and potato callus. Eur J Plant Pathol 100:371379.

Gurr SJ, Unkles SE and Kinghorn JR (1987) The structure and organization of nuclear genes of filamentous fungi. In: Kinghorn JR (ed) Gene Structure in Eukaryotic Microbes. IRL Press, Oxford, pp 93-139.

Harmsen MC, Schuren FHJ, Moukha SM, Vanzuilen CM, Punt PJ and Wessels JGH (1992) Sequence-analysis of the glyceraldehyde-3-phosphate dehydrogenase genes from the basidiomycetes Schizophyllum commune, Phanerochaete chrysosporium and Agaricus bisporus. Curr Genet 22:447454.

Hirano T, Sato T, Okawa K, Kanda K, Yaegashi K and Enei H (1999) Isolation and characterization of the glyceraldehyde-3-phosphate dehydrogenase gene of Lentinus edodes. Biosci Biotechnol Biochem 63:1223-1227.

Irie T, Honda Y, Hirano T, Sato T, Enei H, Watanabe T and Kuwahara M (2001) Stable transformation of Pleuratus ostreatus to hygromicin B resistance using Lentinus edodes GPD expression signals. Appl Microbiol Biotechnol 56:707-709.

Kreuzinger N, Podeu R, Gruber F, Göbl F and Kubicek CP (1996) Identification of some ectomycorrhizal basidiomycetes by PCR amplification of their gpd (glyceraldehyde-3-phosphate dehydrogenase) genes. Appl Environ Microbiol 62:3432-3438.

Kuo CY, Chou SY and Huang CT (2004) Cloning of glyceraldehyde-3-phosphate dehydrogenase gene and use of the gpd promoter for transformation in Flammulina velutipes. Appl Microbiol Biotechnol 65:593-599.

Kuo CY and Huang CT (2008) A reliable transformation method and heterologous expression of $\beta$-glucuronidase in Lentinula edodes. J Microbiol Methods 72:111-115.

Liao X, Fang W, Zhang Y, Fan Y, Wu X, Zhou Q and Pei Y (2008) Characterization of a highly active promoter, PBbgpd, in Beauveria bassiana. Curr Microbiol 57:121-126.

Lima JO, Santos JK, Pereira JF, Resende ML, Araújo EF and Queiroz MV (2003) Development of a transformation system for Crinipellis perniciosa, the causal agent of witches' broom in cocoa plants. Curr Genet 42:236-240.

Lopes FJF, Queiroz MV, Lima JO, Silva VAO and Araújo EF (2008) Restriction enzyme improves the efficiency of genetic transformations in Crinipellis perniciosa, the causal agent of witches' broom disease in Theobroma cacao. Braz Arch Biol Technol 51:27-34.

Meinhardt LW, Bellato CD, Rincones J, Azevedo RA, Cascardo JCM and Pereira GAG (2006) In vitro production of biotrophic-like cultures of Crinipellis perniciosa, the causal agent of witches' broom disease of Theobroma cacao. Curr Microbiol 52:191-196.

Neveu B, Belzile F and Bélange RR (2007) Cloning of the glyceraldehyde-3-phosphate dehydrogenase gene from Pseudozyma flocculosa and functionality of its promoter in two Pseudozyma species. Antonie van Leeuwenhoek 92:245-255

Piechaczyk M, Blanchard JM, Marty L, Dani C, Panabieres F, Elsabouty S, Fort P and Jeanteur P (1984) Post-transcriptional regulation of glyceraldehyde-3-phosphate-dehydrogenase gene expression in rat tissues. Nucleic Acids Res 12:6951-6963.

Punt PJ, Dingemanse MA, Jacobsmeijsing BJM, Pouwels PH and Van den Hondel CAMJ (1988) Isolation and characterization of the glyceraldehyde-3-phosphate dehydrogenase gene of Aspergillus nidulans. Gene 69:49-57.

Punt PJ, Dingemanse MA, Kuyvenhoven A, Soede RDM, Pouwels PH and Van den Hondel CAMJ (1990) Functional elements in the promoter region of the Aspergillus nidulans gpdA gene encoding glyceraldehyde-3-phosphate dehydrogenase. Gene 93:101-109.

Ridder R and Osiewacz HD (1992) Sequence-analysis of the gene coding for glyceraldehyde-3-phosphate dehydrogenase (Gpd) of Podospora anserina - Use of homologous regulatory sequences to improve transformation efficiency. Curr Genet 21:207-213.

Rincones J, Scarpari LM, Carazzolle MF, Mondego JMC, Formighieri EF, Barau JG, Costa GGL, Carraro DM, Brentani HP, Vilas-Boas LA et al. (2008) Differential gene expression between the biotrophic-like and saprotrophic mycelia of the witches' broom pathogen Moniliophthora perniciosa. Mol Plant-Microbe Interact 21:891-908.

Saitou N and Nei M (1987) The neighbor-joining method - A new method for reconstructing phylogenetic trees. Mol Biol Evol 4:406-425.

Sambrook J and Russell DW (2001) Molecular Cloning: A Laboratory Manual. 3rd edition. Cold Spring Harbor Laboratory Press, New York, 999 pp.

Schuren FHJ and Wessels JGH (1994) Highly-efficient transformation of the homobasidiomycete Schizophyllum commune to phleomycin resistance. Curr Genet 26:179-183.

Sirover MA (1999) New insights into an old protein: The functional diversity of mammalian glyceraldehyde-3-phosphate dehydrogenase. Biochim Biophys Acta 1432:159-184.

Vastag M, Kasza Z, Acs K, Papp T, Schwab H and Vagvolgyi C (2004) Cloning and sequence analysis of the glyceraldehyde-3-phosphate dehydrogenase gene from the zygomycete fungus Rhizomucor miehei. Antonie van Leeuwenhoek $86: 111-119$

Wolff AM and Arnau J (2002) Cloning of glyceraldehyde-3phosphate dehydrogenase-encoding genes in Mucor circinelloides (Syn. racemosus) and use of the gpdl promoter for recombinant protein production. Fungal Genet Biol 35:21-29.

\section{Internet Resource}

Witches' broom projetct, http://www.lge.ibi.unicamp.br/vassoura (2004-2008)

\section{Associate Editor: Luís Carlos de Souza Ferreira}

License information: This is an open-access article distributed under the terms of the Creative Commons Attribution License, which permits unrestricted use, distribution, and reproduction in any medium, provided the original work is properly cited. 